\title{
Conceptual Model On Skill - Gap Theory Of Motivation
}

\author{
R. Shanthi ${ }^{1}$, Jai Deo Sharma ${ }^{2}$ \\ \{rshanthicommerce@gmail.com ${ }^{1}$, and sharmjaideo56@gmail.com ${ }^{2}$ \} \\ Associate Professor, Department of Commerce, University of Madras, Chennai, India ${ }^{1}$, \\ Former Director, Indian Overseas Bank, Chennai ${ }^{2}$
}

\begin{abstract}
Motivation is defined as psychological features that stir up an organism to act towards the attainment of the organisational goal. Inner needs, desires, theses etc., are driven by the interest in the task and not influenced by external desires. Employers use reward, recognisation, growth prospect, money, threats and etc., to enhance motivation level. The Skills of employees are vital in determining the level of motivation. Review of literature on relevant variables and the existing theories of motivation reveal scope for evolving a new theory of motivation based on the skill gaps among the employees. It is observed that skill gaps have an adverse impact on the level of motivation. However, the interplay of other factors like training, skill management, compensation, career prospects, leadership styles etc., does impact the level of motivation of the employees. The new theory seeks to enhance the level of motivation of employees by leveraging these factors and redesigning HR policies.
\end{abstract}

Keywords: Skill Gap, Motivation, Required Skill, Acquired Skill, Employee Behaviour, Performance.

\section{Introduction}

The success of an organisation would largely depend on its planning and set competitive goals in the given business environment and execute the plan well. In the age of innovationdriven technological advancement, technology has been playing an important role in ensuring the success of an organisation. However, the fact remains that technology continues to be subservient to its masters - human resources. It brings to fore the importance of human resources even in the technology-intensive business organisations.

It is said that - It is not always the best-equipped army that wins the war; It is the bestmotivated army that wins the war.

In a competitive business world, it is considered the survival of fittest. The organisations which can deliver the best product or service at a most competitive price, have better chances of success and survival in long run (Kogut, B., \& Zander, U. 1992). It is thus clear that technology and human resource play a vital role in ensuring attainment of an organisational goal and thereby its success. Another component of the business processes is its cost-effectiveness at marketplace (Neely, A.,\& et. al., 2005). Successful organisations master the art of achieving 
organizational prosperity through employee motivation. It is therefore pertinent to understand the meaning of 'Motivation' in an organizational context (Rousseau, D. M., \& Fried, Y. 2001).

\section{Motivation}

Motivation is described as an act or process of giving someone a reason for doing something (Davidson, D. 1963\& Dornyei, Z., \& Ottó, I. 1998). It forces or influences a person to do something. The Motivation has been derived from the word 'motive' which means needs, desires, wants or drives within the individuals (Kleinginna, P. R., \& Kleinginna, A. M. 1981). Satisfaction of these variables in a human being helps in accomplishing the goals (Sheldon, K. M., \& Elliot, A. J. 1999). In a theoretical context, motivation is used to explain the behavior and impulse of a person that cause him to act (Ainslie, G. 1992). Motivation therefore is not visible from outside but can only be noticed by regularly observing the behavior of a person. In the organizational context, motivation is defined as a process that initiates and guides the goaloriented behavior in a person. It is considered an outcome of interaction between conscious and unconscious factors like intensity of desire, incentives or reward associated with the goal, expectation by self, organisationand peers (Locke, E. A., \& Latham, G. P. 2002).

Motivation is also defined as a psychological feature that arouses an organism to act towards a desired goal while eliciting controls and exhibiting goal-directed behavior in a sustainable manner (Cox, W. M., \& Klinger, E. (Eds.). 2011). It is a driving force that compels or reinforces an action towards a desired goal. This definition of motivation leads us to believe that it has its roots in psychological, behavioural, cognitive and social concepts and aims at maximizing the well being and minimising a physical pain (Fiske, S. T., \& Taylor, S. E. 2013 \& Eccles, J. S., \& Wigfield, A. 2002).

\section{Intrinsic Motivation}

The inner conditions of a human being, such as wishes, desires, needs etc., activate him to move in a particular direction. Hence it is inferred that it is the inner state of our mind that primarily activates and directs our behavior towards attainment of the goals. It is driven by his interest in the task itself and exists within the individual rather than relying on external pleasures or desires for the rewards. Intrinsically motivated people are more likely to engage in the task voluntarily and willingly for which they also make sustained efforts to improve their skills and capabilities as that would help them in giving enhanced performance outcomes (Wigfield, A., \& Guthrie, J. T. 2000; Spencer, L. M., \& Spencer, P. S. M. 2008 and Stipek, D. J. 1996).

\section{Extrinsic Motivation}

Extrinsic factors are generally created by the employers and include rewards, recognition, growth prospects, money, threat of punishment etc. These factors make an employee channelize his energy in the direction to attain the goals set by the organisation. Extrinsic motivation is therefore described as inspiring an employee to work for accomplishment of the objectives of the organization (Shamir, B.,\& et. al., 1993; Manzoor, Q. A. 2012 and Meyer, J. P., \& et. al., 2004). 
High level of motivation helps creating a strong bond between employees and organisation while helping in stimulating a desire and energy to ensure an interest in job and commitment to the organisation so as to attain the set goals in a timely and orderly manner.

\section{Review of Literature}

Linjuan Rita Men (2014)explored that the relationship among transformational leadership, symmetrical communication and behavioural outcomes of the employees. The researcher adopted empirical research design to explore the influence of transformational leadership dimension on symmetrical communication and relationship of employee in the organization. Further, the author examined the influence of employee relationship perception on employee orgnisational advocacy in terms of employee motivation. The results indicates that employees commitment or advocacy is significantly determined by employee relationship communication and leadership styles. To conclude, accuracy of the information communicated at the all levels of emplacement is plays an important role in determining the organistional objectives attainment. The role of leader should be more motivated and open for opinion within the limited boundary in the organization.

Voon., Lo., Ngui., and Ayob (2011)conducted an exploratory research study to examine the leadership style influence on the job satisfaction of the employees with respect to public sector organizations in Malaysia. The researchers identified that to types of leadership style such as transactional leadership and transformation leadership is prevailing in the public sector organisation of the selected study area. The results reveal that leadership styles played a significant role in determining job satisfaction of the employees. Further, the author suggested that by effective team building and providing conductive working environment will encourage the employee to attain higher job satisfaction. To conclude, the transactional leadership style have positive impact on job satisfaction whereas, transformational leadership has negative relationship with job satisfaction in selected Government organizations.

Elnaga., and Imran (2013)conducted a qualitative study to understand the framework of effective training on employee performance for the self development within the organizational premises. The researcher suggested the developmental check list for the top level management to effectively redesign the training programme for the enrichment in the employee performance. The researchers provide various insights to explore the fundamentals of designing effective training programme by applying different layers of analysis. Further, the researcher concluded that higher is the training effectiveness, higher is employee performance.

Aasheim, Cheryl L., Li, Lixin., Williams, Susan (2009)examined the skills required for graduates at entry level for information technology related jobs and non-information technology related jobs. The researchers conducted primary survey to experience the skills acquisition in the different aspects such as, communication skills, interpersonal skills, analytical skills, leadership skills and etc., in their curriculum. The empirical evidences proves that knowledge with respect to specific industry, programming languages and life cycle methodologies have significant difference with respect to their skills acquisition for Information Technology (IT) and Non-Information Technology (IT) based employment. Finally, the authors concluded that personality traits and skills acquisition in the graduation of students leads them to procure the entry level needs for IT and Non-IT firm employment. 
Gardner., Wright., and Moynihan (2011)carried an exploratory research study to examine the determinants of aggregate voluntary turnover with the mediating effect of collective affective commitment of employees. The authors stated that motivation, empowerment and skillenhancing practices are plays an imperative role in inducing and determining the aggregate voluntary turnover of the employees. The casual relationship indicates that motivation, empowerment and skill enhancement are mutually exclusive to each other and it is also significantly differentiated by each items perception among the employees. Further the results prove that union, unemployment, proportion of female, educational qualification and tenure has significant impact with the mediation of collective affective commitment of the employees.

Madan and Bajwa (2015) Authors opined that the compensation management is very important for employees but it should be linked with their productivity. The employees should be given proper allowance facility, salary and job security, according to the market trend. In this the variables that contribute to compensation management were promotion system, performance reviews and wages and salary. The factors which influence motivation level of employees in Malviya Urban Cooperative Bank is job security, workplace flexibility and performance appraisal. Therefore the study revealed that there is a strong positive correlation between compensation management and employee motivation. Therefore the banks should make use of both monetary and non-monetary incentives to motivate the employees.

Robert C. Merchant (2009)the author discussed that the consciousness of employees with respect to their career development opportunity role in enriching the organizational effectiveness through effective employee development. The researcher made an attempt to identify the imperativeness of designing the career development program and it's role in determining the employees development. Further, author explored the importance of acquiring different skills to survive in the 21 st centuries competitive work environment. Finally, the author suggested that effective training programme is need of the hour for horning the career development skills among eligible and competent employees.

Yongbeom Kim., Jeffrey Hsu., and Mel Stern (2006)conducted an empirical study to explore new curriculum and develop specific implications to build an enhanced and effective information system programme in order to meet specific industry needs for the effective change adoption. The researchers classified the respondents into information system focused group and non information system focused group with a platform of different designations such as managers, designer, programmer, executives and supervisory staffs. The result shows that based on the experience of the employees in their respective designation play a vital role in acquiring the information system skills. The authors suggested that integrated and objective oriented information system course will facilitate to meet specific industry needs. To conclude, it is very imperative that the trainees should possess up-to-date information system skills and information technology skills to survive in the perfectively competitive business environment.

Kavita Rani and Diksha Garg (2014)have conducted an empirical investigation to explore the effectiveness of training and development programmes conducted by banks for their employees. The researchers adopted survey method to collect responses in the form of opinion from bank employees with regard to their training and development programme effectiveness. The empirical evidences indicate that the trainees opine that training and development programmes have higher effectiveness with regard to skill development, performance enrichment and career development opportunities in their respective designations. Further, the authors concluded that 
trained employee will provide higher quality of services to their customers with a help of integrated, effective and proactive training and development strategies in the banking industry. Finally, they suggested nurturing effective training programme to empower and fulfill the employee skill gap to elucidate sophisticated outcomes.

Karthikeyan., Karthi., and Shyamala Graf (2010)conducted a hypothetical study in order to explore the effectiveness of training programmes conducted by selected banks in tiruchirappalli district of Tamilnadu. The researchers employed well designed instrument to collect opinion on training programmes among trainees of selected programmes. The result indicates that training programmes have positive impact among the employees and it contributes for growth of the selected banks. Further, the authors proven that there is no significant difference in the training programmes conducted by different banks located in the study area. To conclude, learning objectives, input, job effectiveness, relationships and behavior of training programme contributes for the overall effectiveness of training and this leads to the growth of the selected banks.

Anna Salanova and Sanni Kirmanen (2010)examined the relationship between employee satisfaction and work motivation. The primary survey is clearly indicates that respondents possess the higher satisfaction and it have significant relationship between work motivation. The motivation in form of non-monetary has higher importance to enrich and expand the employee satisfaction in selected companies. The researcher concluded that financial rewards and any recognisation plays an important role for the betterment of employee satisfaction and effective human resource management.

Goodman., Evans., and Carson (2011)conducted descriptive and empirical study among the working adults to identify the relationship between organizational politics and stress through accountability. The result indicates thatquality concerns stress, responsibility pressure stress and job and non-job conflict stress will leads to the higher level perception on accountability and politics in the organization. The longitudinal examination of data supports that the stress concerns have an interaction effect with organizational politics and culture.

Marcel Simard and Alain Marchand (1997)examined the influence of micro and macro organizational factor on driving the work groups to accomplish organizational objectives with safety measures. The researcher discussed the role of propensity of work groups towards attaining the log-term vision and mission of the manufacturing companies. This empirical evidence supports that the socio economic characteristics of the employees is determining the safety management behavior and supervisor co-operation. Further, it is evident that social relationship among the employees, organizational factors, supervisors experience and safety management have positive effect of propensity of work groups in the manufacturing companies and the authors suggested to develop, effective safety programmes and effective regulation mechanism to achieve work group goal.

Malhotra, G. (2011) studied the impact of pre and post liberalisation impact among Indian industries in the state of Gujarat. This study primarily aims to explores overall economic development through various manufacturing units located in the study area. The result reveals that NVA, number of registration, value of output and employment prospects are contributing to the development Gujarat economy in the pre and post liberalisation era. Therefore, the author 
suggested Indian Government to focus various new economic reforms which contributes the employment generation and industrial growth in the country.

Jothi Baskara Mohan (2013) investigated the influence and effectiveness of HRM practices on globalisation of Indian business with the aim of exploring various challenges for business issues in the competitive environment. This study focuses on cost pressure, retaining leaders and talent and addressing regulatory changes. Further, the researcher made an attempt to explore various major challenges in human capital management, strategies for engaging work force effectively and retaining the key employees for the purpose of improving the leadership capabilities among employees of Indian organisation to meet global standard in 21 st century.

Abbasi, and et al., (2018) made an empirical investigation to identify the gap expected by the managers and actual skills possessed by business graduates employed in the banking industry. The researchers have adopted a survey method to know the perception of the graduates regarding imperativeness of employability skills leads to be possessed by young bank officers in the industry. The result indicates that employability skills of the graduates expected by the managers are not matched by the business graduates chosen for the study. Further, this research study made an important contribution that still there is a huge skill gap between academiaindustry.

Shammy Shiri (2014)studied the face of globalisation-integration and transformation of human resource management in strategic business operation. This study aims to analyse issues and challenges confronted with globalisation and HRM in global market. The researcher made an attempt to understand with the help of base line information and survey to investigate HR as a strategic partner. Researcher concluded that the HR practitioners are needed to be focus various leadership skills which enables them to perform effectively in the globalisation context.

Kuchinke, K. P. (1998) made an attempt to carry a cross-sectional study to investigate influence of different leadership style on subordinates satisfaction level and work performance. The researcher has selected US and German employees working in manufacturing industries are selected for the study. The researcher has adopted a survey method to gather information about leadership styles and its impact on work performance. The result indicates that these factors are highly correlated to each other and German employees have lower perception towards their leadership styles and job commitment in the country. Finally, the author suggested to implement the international management practices and leadership development in their usual activities.

Kim, J. H. (2011)studied the role leadership competency in human resource development with the primary objective to test the leaders self efficacy and imitative with respect to innovation. The author has developed model of issue leadership and test this aim. The researcher has adopted a survey method to gather information through structured questionnaire from the respondents. The result indicates that leader's initiative and self efficacy are significantly determining issue leadership management practices in their organisation. Finally, the researcher concluded that innovativeness and leader effectiveness plays a vital role in determining the leader'sinitiative at different levels of business.

Salvo, V. S., \& Larsen, J. K. (1987) attempted to identify the importance of communication skill in organisational life. This study primarily aims to generate the list of various key drivers determining the information follow through a contingency approach. Further, this study also 
aims to compare the contradiction and methodological differences with respect to contextual contingency. Results reveal that five major components such as, exchange of routine information, soliciting giving feedback, listening and relationship building are the major determinants of communication skill effectiveness in the organisational environment. In addition, the researchers have classified that upward, downward and horizontal communication situations are highly correlated to occupation, direction and position of the employees.

Lynham, S. A. (1998) made an attempt to develop a model based on the existing literature review for responsible leadership performance. The model developed for the responsible leadership for performance consists of a paradox with self interest, pressure, complexity, diversity and solution. Further, theauthor critically examines the pursuit of control and discrete boundaries for the development of core leadership practices and leadership needs. Finally, the author concluded that performance is a important parameter has to be necessarily focus for development and evaluation of responsible leadership model.

\section{Research Gap}

After reviewing the literature in respect of relevant variables used in the theory of motivation and also reviewing the existing theories of motivation, it was found that there existed scope for evolving a new theory of motivation. The existing theories of motivation studied included the following:

a) Maslow's Need Heirarchy Theory

b) Alderfer's ERG Theory

c) Herzberg's Two-factor Theory

d) McClelland's Learned Need Theory

e) McGregor's Theory X and Theory Y

f) Urwick's Theory Z

g) Argyris's Theory

h) Vroom's Expectancy Theory

i) Porter and Lawler Expectancy Theory

a. Maslow's Need Hierarchy Theory (1943) explored the five essential basic needs to optimal human existence in a hierarchy from low-high which are physiological, safety, social, selfesteem and self-actualization needs. The theory states that people are motivated by unmet needs from a lower to higher level of needs as it's a gradual process. Individual could be motivated by more than one need at a time and continue to be motivated by a need until it satisfies. Maslow described when the higher level are satisfied the people could realize their fullest potential.

b. Alderfer's ERG Theory (1969) developed Maslow's hierarchy of need theory by categorizing the hierarchy into ERG theory (Existence, Relatedness and Growth). The theory includes satisfying higher needs with lower level desires or behavior in different categories result in different behavioral predictions. Existence needs are vital to survival which includes Maslow's physiological and safety needs. Relatedness needs involves how people deal with social and interpersonal relationships with significant individuals. Growth needs are satisfied by productive and creative efforts, it includes Maslow's self-esteem and self-actualization needs. 
c. Herzberg's Two Factor Theory(1959) explored the area of job satisfaction under two factors which are Motivators or intrinsic factors contributes to job satisfaction and Hygiene or extrinsic factors contributes to job dissatisfaction. The job satisfaction and dissatisfaction are separate dimension there are not under the ends of single dimension. Theory proposes that paying more attention to motivator's factors will increase the job satisfaction through an improved performance of individual and attention to the hygiene factor will decrease the dissatisfaction but it will not reflect in the overall satisfaction as no improvement in the performance.

d. McClelland Learned Need Theory (1984) developed a descriptive set of factors which reflect a high need for achievement. The theory proposes a strong need in a person motivates to use behavior which leads to satisfaction of the need. The main theme of the theory is that needs are learned through copping with one's environment. The need for achievement or $\mathrm{n}$ Ach involves the desire to independently master objects, ideas and people to increase one's self-esteem through the exercise of one's talent.

e. Mc Gregor's Theory X and Y (1960) explored the nature of humans in the work place. The assumptions are the basis of Theory $\mathrm{X}$ and Theory $\mathrm{Y}$ teachings, the manager operated under a set of assumptions he called classical management, or Theory $\mathrm{X}$ management. Theory $\mathrm{X}$ managers emphasize the chain of command, and close supervision of subordinate behavior along rigidly defined behavioral parameters. McGregor proposed a new set of managerial assumptions as Theory Y management, in order to solve and overcome problems where manager $\mathrm{Y}$ assume that the people they supervise would solve work related problems by themselves.

f. Lyndall F. Urwick Theory Z (1970) proposed a theory for the motivation among employees through management actions. The people would be ready to direct their behavior towards organization goals under two conditions, as each individual should know the organizational goals and contribute his attempts to the accomplish it and each individual should be confident that the realization of the organizational goals has a satisfaction positively. This theory reflects about the behavior of the individuals in motivation through a new theory $\mathrm{Z}$.

g. Argyris's Theory (1978) explores the human nature and behavior as a person's development is processed along a continuous break of an immaturity situation to a maturity situation. A mature person is distinguish for being active independent, self-confident and self-controlled. On the contrary, an immature person is passive, dependent. The theory proposed to acquire cognitive abilities to have a greater self-competence and confidence. Interventionists must facilitate a learning environment, to explore psychological defenses and resistances to change through group defensive operations.

h. Vroom's Expectancy Theory (1964) proposed the importance of motivation and offers critical value for marketing research. This theory examines motivation from the perspective of why people choose a particular action or behavior and used to predict how individuals make choices between different courses of action. The motivation and effort will be high when the performance and outcome are high. The theory maintains that individuals make comparisons among motivational forces values for alternative behavior possibilities in order to choose what to do.

i. Porter - Lawler Expectancy Theory (1968) explored the motivation process with nine variables, for the proper analysis of complex processes that determine level of motivation. This 
model is the most comprehensive theory of motivation which explains the complex process of motivation diagrammatically. The fundamental aspect of the model is about the relation between performance and satisfaction. Theory is built on expectancy aspect, with a substantially more complete model of motivation. This model is inclusive of major significant attempt to explain how motivation works.

It was found that there existed scope for evolving a new theory of motivation which would underscore the importance of availability of skill sets in the organization. It is in this background the proposed Skill Gap Theory of Motivation is propounded in the following pages.

\section{Proposed Skill-Gap Theory of Motivation}

An examination and review of various existing theories of motivation reveal that job satisfaction and career orientation are part of motivational dimensions. It is therefore inferred that these are the products derived out of motivation. During the research study it was found that skill gaps which emerged during the last two and half decades largely due to emergence of new business dimensions, regulatory framework, technology etc had an adverse impact on the level of motivation of managerial cadre employees of the Public Sector Banks in India.

Seamless integration of the economies of the world had created an enhanced level of globalization. Since the banking is an important channel for settlement of trade related transactions, it also leads to transformation of banking business and processes so as to align with international practices. Technology being an enabler played important role in evolving the new normal in banking, thus giving rise to urgent need for newer skill sets to cope up with the emerging needs of business.

Equipping the employees with newer skill sets posed a serious challenge before the banking community. The studies revealed that the skill deficit impacted the morale of the employees in the banks adversely. New entities did not face serious problem as they hired skilled people suitable for the job. But the existing institutions saddled with legacy issues were adversely impacted by the resultant skill gaps among the employees.

It was under these circumstances, that the morale of the employees witnessed a southward trend during the period of globalization which transformed the business of banking multifold. It was discovered during the research that none of the existing theories on motivation deals with the role and influence of inadequacy of skills on the level of motivation. Evolution of a new proposed theory is expected to make significant contribution to the existing literature on motivation.

This theory essentially takes into consideration four important elements associated with measurement of the level of motivation. These elements are:

a

1. Skills

i. Aggregate skills - a) Self-Skills

b) Team-Skills 

ii. Required skills
iii. Acquired skills
iv. Skill Gap (ii - iii)

2. Environmental Factors

i. Business Environment (Macro)

ii. Organisational Factors (Micro)

3. Workplace Factors
iii. Training and Development
iv. Skill Management
v. Monetary Compensation
vi. Career Prospects

4. Professional Factors
vii. Leadership Style
viii. Peace of Mind
ix. Accountability Perception

Using the above elements, the level of motivation can be measured with the help of following equation:

$$
\text { Motivation }=\frac{1}{\text { Skill Gap }}+\mathrm{F}(\mathrm{W}+\mathrm{P})
$$

Where -

Skill Gap $=$ Required Skills - Acquired Skills

$\mathrm{F}=$ Factors

$\mathrm{W}=$ Work Place Factors

$\mathrm{P}=$ Professional Factors

The above equation would show that,

- Lower the skill gap, higher will be the motivation

- Higher the skill gap, lower will be the motivation

- Work Place Factors and Professional Factors may also impact the level of motivation either way

The research also showed that the job knowledge enhances the confidence of the employees at work place.

Skill-Gap Theory of Motivation can be explained hereunder with the help of a Model and by providing an explanation to the various components: 


\section{JAIDEO’s SKILL GAP MODEL OF MOTIVATION}

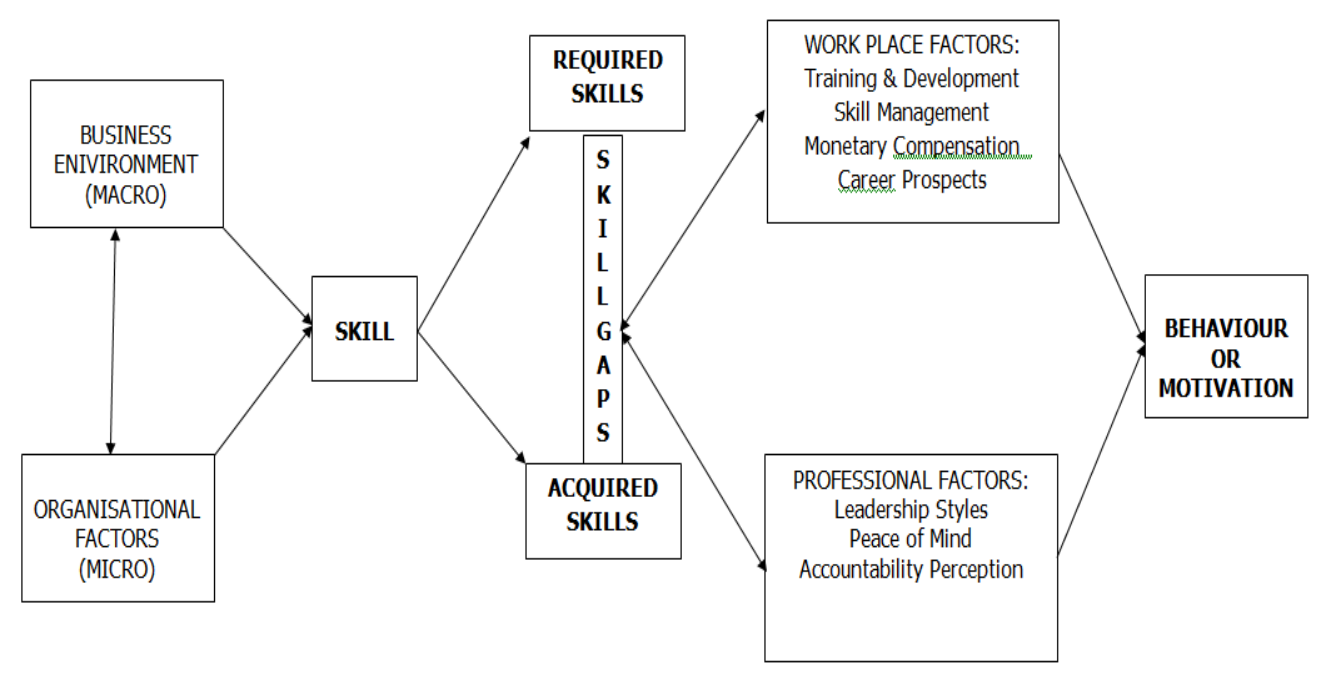

Fig. 1. JAIDEO’s SKILL GAP MODEL OF MOTIVATION.

\section{Business Environment}

The business of an enterprise is conducted in the given business environment and also within the framework of government policy and regulatory directions. Since business environment and government policy and regulatory directions will govern all the firms, these two factors are considered constant and will have similar impact on all the enterprises and its employees. A descriptive analysis of the data collected showed that $83.04 \%$ of the respondents shared the same view.

However it would be appropriate to describe some of the common and usual factors hereunder for a better understanding of the subject:

General Environment: The business of banking essentially involves financial intermediation. The banks therefore mobilize the surplus resources of the society and invest and lend to those who need these resources for economic, productive, personal and consumption purposes. The propensity to save and propensity to deploy these resources would thus determine the level of business of banking. The higher level of business would necessitate more number of employees. But marginal and moderate increase in the business can also be managed quiet effectively by enhancing the level of motivation of the exiting employees. The variables like reward, recognition, incentives, career prospects, training and development on one hand and technology enhancement, business process re-engineering etc. on the other hand have significant impact on the level of job satisfaction and eventually on the level of motivation of the existing employees. 
Government Policies: The Government formulates various policies like Trade Policy, Industrial Policy etc. to necessitate channelization of bank credit to specified sectors of economy. These policies provide a fairly stable macro environment. Such policies may lead to the need of newer skill sets of bank employees. Re-skilling and Up-skilling of employees being a necessary condition shall help bridge the skill gaps. Net skill gaps will have an impact on the level of motivation of the employees.

Regulatory Policies: The business of banking is conducted under the Regulatory Policy Guidelines of the Central Bank of the country. The regulatory guidelines are fairly stable and thus provide a uniform and stable macro environment for the business to be conducted. However, as and when there are changes in the areas such as Exchange Rate Management, Credit and Monetary Policy issues, Accounting Norms and Standards, the need for re-skilling and up-skilling becomes inevitable. The level of re-skilling and re-positioning coupled with the quality of such initiatives will impact the skill levels of the employees and help maintain the level of motivation required for smooth conduct of business.

\section{Organisational Factors}

The Organizational Factors can be described as the customs and practices of the organization, thereby constituting the organization culture. Adherence to systems and procedures would reflect the attitude of the employees and eventually form part of organizational culture. Other organizational factors may include marketing techniques segmentation, advertising, delivery channels, customer service, grievance redressal mechanism, customer care etc. These factors remain largely constant in the organization. Though these factors play an important role in determining the level of motivation of the employees, the variance in the level of motivation due to these factors is negligible.

\section{Skills}

Given the macro and micro environmental factors of the business enterprise, success of business would depend on the level of skill sets and their effective management.

Skills have been taken as an aggregate of the skills of the manager and also the skills of his team members. An objective analysis and assessment of the job will help determine the needed skill sets for the given tasks. This is known as skills required. Similarly an analysis and assessment of the skills possessed by the manager and the members of his team will show the availability of skill sets for smooth accomplishment of the given task. As long as the available skills equal the required skills, the gap between the required skills and acquired skills will be zero. It is at this zero level of a skill gap, the probability of level of motivation being high is high. Whereas if there is a gap between the required skill sets and acquired skill sets, the level of motivation is likely to be lower. It shows that higher skill gaps in aggregate terms will lead to lower motivation. It therefore establishes that skill gap has an adverse impact on the level of motivation. There is therefore an inverse relationship between the level of motivation and the quantum of skill gap, other factors being constant.

The level of motivation so determined will also be influenced by other factors. It is therefore considered appropriate to discuss other factors too. 


\section{Work Place Factors}

The Work Place Factors are described as those organizational and HR interventions having potential of impacting the individual and collective level of motivation in the organization. However, such Work Place Factors may have positive or negative impact on the level of motivation. Some of the OD and HR interventions used by the organizations to impact the level of motivation are discussed hereunder:

Training and Development: Trainings have an important role in development of the leaders and also the employees. Trainings are essentially required to re-skill and up-skill the employees and equipped them to meet the challenge of changing environment including demand, technology, market etc. The requirement of training is therefore needed to be assessed on a regular basis so as to ensure that the employees and manager remain relevant to the task on hand. Adequate and relevant training to employees and manager will have positive impact on the level of motivation. The lack of proper training is likely to widen the skill gaps and thus have an adverse impact on the level of skills and in turn the level of motivation. A descriptive analysis of the data collected showed that $82.40 \%$ of the respondents shared the same view.

Skill Management: Business is conducted in a dynamic environment. Innovation and Research play an important role in designing and evolving new products in a cost-effective manner. The market demand for newer and diversified products also plays an important role in the development of new products. Such situations will require new skill-sets to handle design and production of new products. It will create a need for skill enhancement. The absence of newer skills will lead to skill mismatch and in ultimate analysis adversely impact the level of motivation. It would therefore warrant re-skilling and/or up-skilling of the employees so as to keep them relevant to the job and thus prevent deterioration in the level of motivation. A descriptive analysis of the data collected showed that $70.20 \%$ of the respondents shared the same view.

Monetary Compensation: Monetary Compensation is an important component of human resource policy as it has significant impact not only on the level of motivation of the existing employees but also plays an important role in influencing the decisions of prospective employees to join or not to join the organization itself. A fair compensation is therefore likely to have positive impact on the level of motivation. The fairness of the compensation encompasses internal relativity and also external relativity as the employees would have a tendency to compare their monetary compensation with their peers within the organization and also the other organizations in the industry. Compensation is also considered as a reward for the role function, level of the employee in the hierarchy, responsibility and accountability. Any feeling of en unfair treatment in terms of adequacy and proportion in the quantum will have an impact on the level of motivation of the employee. A descriptive analysis of the data collected showed that $72.28 \%$ of the respondents shared the same view.

Career Prospects: Prospects of a better career within the organization or even outside will have positive impact on the level of motivation. Such of those employees who do not visualize any career progression either on account of their advanced age or on account of there being little scope to rise beyond the existing level in the field of work, are more likely to have such situations adversely impacting the level of motivation. It is therefore considered important to keep in view the aspirations of the employees with respect to their career prospects. Keeping 
their hopes of career progression realistically alive would play a vital role in keeping the morale and motivation of employees. Intermittent recognition and reward for good work in unbiased and appropriate manner would also act as motivating factors for the employees. A descriptive analysis of the data collected showed that $82.14 \%$ of the respondents shared the same view.

\section{Professional Factors}

Leadership Style: The style of leadership of a manager will have impact on not only his own level of motivation but may also impact the level of motivation among his team members or the subordinates. A suitable change in the leadership style may help enhance the level of motivation. Some leaders would find it difficult to tweak their style of leadership and in such cases other interventions like change of leader or his team members may lead to desired results. Such situations may call for evolving and formulating suitable relocation policies in the organization with necessary safeguards to prevent emergence of a feeling of being discriminated. Selection of new leaders and team members would need to be done keeping in view the requirement of job and the circumstances which led to the need for relocation of leader or the team members. A descriptive analysis of the data collected showed that $56.28 \%$ of the respondents shared the same view.

Peace of Mind: Peace of mind of an employee is an important component and also an outcome of his job. The job satisfaction makes a positive contribution to the peace of mind of an employee and an employee with peace of mind makes better and positive contribution to his performance outcome. Accomplishment of a job in a manner that it adds to the delight of the customer or adds value to the organization, is considered a vital factor contributing to enhance the level of job satisfaction of the employees. It eventually would play an important role in ensuring elevated level of motivation. A disturbed mind will have an adverse impact on the level of motivation. A descriptive analysis of the data collected showed that $82.14 \%$ of the respondents shared the same view.

Accountability Perception: In any business organization the responsibility entails accountability. Higher the responsibility, higher would be the accountability. In business organizations, the nature of responsibility at different levels of hierarchy may have financial implications of different nature. Earning profit is an important objective of business organizations. The level of motivation has an important bearing on the performance outcome and hence the fear of accountability of a punitive nature may compel an employee to deliver better performance. A lack or absence of punitive measures may also lead to more creativity and an atmosphere of fearlessness in the organization. Such practices may have better impact on the culture of the organization thereby leading to the higher level of overall motivation. The employee shall therefore be motivated in his role function. If non-performance or nonachievement of organizational goals does not entail punitive action, an employee may not deliver his best performance. He may prefer to operate below his potential. An employee's perception about accountability therefore plays an important role on the level of motivation. A descriptive analysis of the data collected showed that $72.60 \%$ of the respondents shared the same view.

It is thus seen that the gap in skill-sets have significant influence on the performance outcomes, employee behavior and ultimately on the level of motivation of an employee. However, by tweaking in the Workplace Factors and Professional Factors on a positive side 
from time to time, the level of motivation can be enhanced. Since the Business Environment and Organizational Factors do not change frequently, their impact on the level of motivation would not vary much over time in otherwise dynamic organization.

\section{Recommendations for Motivation Enhancement}

The following initiatives are recommended for enhancing the level of motivation of individual employee and also the teams at workplace:

Consistent approach to simplify processes through technology leverage: Technology plays an important role in simplification of processes and enhancing the level of efficiency of delivery of service. It helps the business entities to constantly innovate to simplify the processes so as to save on time and cost. It improves the productivity/profitability and thus may lead to higher job satisfaction among the employees who will feel motivated by new simplified processes through technology leverage.

Skill updation/up gradation of employees on a regular basis: Change is the constant feature of technology. The technological innovation and advancement are taking place at a fast pace. Even before the employees get comfortable with the new technology, it becomes old and obsolete. It becomes imperative for re-skilling the employees to get the best out of them and leverage the technology. Inability to do so would have negative impact on the level of motivation of the employees while re-skilling will result in positive employee motivation. It is therefore in the best interest of the organization to keep the individual and collective skill gaps at the lowest possible level so as to maintain higher level of motivation in the organization.

Quick adaptation to regulatory and policy changes: The skill levels play an important role in helping the employees adapt to new regulatory and policy changes. The employees feel empowered. A quick and smooth adaptation would reduce the level of anxiety and uncertainty among the employees leading to higher level of job satisfaction and motivation. The training and mentoring would play a positive role in ensuring high motivation.

Redesigning hierarchical pyramid to create new position for career progression: The prospects of Career Progression in an organization keep the employees hopeful of their betterment in the times to come. It is this hope which would make them conduct well and give their best performance so as to earn their promotions and have the best possible career progression. In most of the organizations, the hierarchy is in the shape of pyramid. It may create situations where the people in the higher levels of pyramids are younger and there is very little likelihood of their moving from their position to create a vacancy for their juniors to get elevation. It would therefore be desirable to re-design the hierarchical pyramid by creating new opportunities so that the employees in the lower part of the pyramid have hopes of timely and fair career progression. It will keep them motivated in the organization.

Offering market-related compensation and adding new non-monetary initiatives: Monetary Compensation is considered as one of the important tools of motivating the employees. It happens not only at entry level but also during the journey of an employee within the organization. It is therefore pertinent to adopt fair and market related monetary compensation policies. However, there may be organizational constraints sometimes making the enhanced monetary compensation an impractical proposition. Under such circumstances, 
non-monetary initiatives can play an important role in enhancing the sense of belongingness among the employees and keeping their motivational level high even at the given level of monetary compensation.

Changing the accountability perceptions from punitive to preventive: Accountability is an important aspect of Government and Public Sector Organizations. In Public Sector commercial organizations like banks, the decisions are taken within the framework of rules and guidelines but there is an element of subjectivity in evaluating the proposals involving a futuristic approach. The decisions are therefore also based on assumptions about the business environment in the years to come. Those assumptions which look realistic at the time of taking decision may not come true in real time. If such decisions are viewed with the hindsight at a later date, it may seem to be a bad decision and sometimes even motives can be attributed to fix accountability. The possibility of such an eventuality may create risk aversion tendencies leading to lower performance levels in spite of the existence of higher skill levels. It is therefore important to pursue an objective accountability policy which is more tweaked towards preventive than the punitive propositions.

A good blend of the above factors can help enhance the motivational level of employees. Better management of collective skills of the employees will also have a positive impact on the employee motivation. The New Skill Gap Theory of Motivation will contribute immensely to the existing literature on the subject.

\section{Research Objectives}

- To identify the skill gaps caused by the impact of globalization on different business dimensions of Indian Public Sector Banks and measure the effect of skill gaps on the level of motivation.

- To assess the adequacy of human resource initiative towards leadership development, compensation, performance evaluation, employee acquisition/retention/attrition and accountability in Indian Public Sector Banks.

- To evaluate the relationship between post globalization human resource initiatives and the level of job satisfaction, career orientation and motivation among the officers of Indian Public Sector Banks.

\section{Research Methodology}

The study was conducted by soliciting responses in the form of primary data from the managerial cadre employees across the grades working in 25 PSBs including State Bank Group at metro, urban, semi-urban and rural centres across India. IDBI Bank, though a Public Sector Bank, has been excluded from the purview of study since its HR Policies are dissimilar to the policies of other 25 Public Sector Banks (PSBs). 
Instrument was developedin the absence of any validated tool on the subject of the research study. The questionnaire was constructed on the basis of experience gained during the research study. It was put to use for conducting pilot study covering three Public Sector Banks (PSBs) at Chennai. After testing its reliability through an analysis where Cronbach's Alpha value was found to be 94 per cent and factor analysis of 96 per cent, the instrument was considered fit for use. However, it was further fine tuned to make it comprehensive and userfriendly more particularly in the absence of any pre-validated scale. Few questions were removed and few new questions were added. The pilot study questionnaire consisting of 185 statements was reduced to 154 statements to make it more effective.

Quota sampling has been used by the researcher to select samples based on reach or access of the locations from where the data has been collected for the research study. Quota sampling method was used to ensure that a fairly proportionate sample is collected from each group of bank according to their size. The number of bank wise respondents was largely determined on the basis of the size of the banks in terms of business mix. The details of sample size are as follows:

Table 1. Sample Size and Questionnaire Distribution.

\begin{tabular}{|c|c|c|c|c|c|c|c|}
\hline \multirow{2}{*}{$\begin{array}{c}\text { Particulars } \\
\text { of } \\
\text { Questionnai } \\
\text { re }\end{array}$} & \multirow{2}{*}{$\begin{array}{c}\text { Junior } \\
\text { Manageme } \\
\text { nt }\end{array}$} & \multirow{2}{*}{$\begin{array}{c}\text { Middle } \\
\text { Manageme } \\
\text { nt }\end{array}$} & \multirow{2}{*}{$\begin{array}{c}\text { Senior } \\
\text { Manageme } \\
\text { nt }\end{array}$} & \multirow{2}{*}{$\begin{array}{c}\text { Tota } \\
1\end{array}$} & \multicolumn{3}{|c|}{$\begin{array}{c}\text { Public Sector Banks } \\
\text { Categorised (Annexure } \\
\text {-1) }\end{array}$} \\
\hline & & & & & $\begin{array}{c}\text { Larg } \\
\text { e } \\
\text { Bank } \\
\text { s }\end{array}$ & $\begin{array}{l}\text { Mediu } \\
\text { m } \\
\text { Banks }\end{array}$ & $\begin{array}{c}\text { Small } \\
\text { Bank } \\
\quad \text { s }\end{array}$ \\
\hline Issued & 250 & 750 & 200 & 1200 & & & \\
\hline $\begin{array}{l}\text { Filled \& } \\
\text { Returned }\end{array}$ & 214 & 690 & 145 & 1049 & & & \\
\hline $\begin{array}{l}\text { Partially } \\
\text { Rejected }\end{array}$ & 111 & 271 & 17 & 399 & & & \\
\hline Found Valid & 103 & 419 & 128 & 650 & 313 & 182 & 155 \\
\hline
\end{tabular}

\section{Confirmatory Factor Analysis (CFA) of Research Variables}

Table 2. Model Fit Index Acceptable Threshold Levels. 


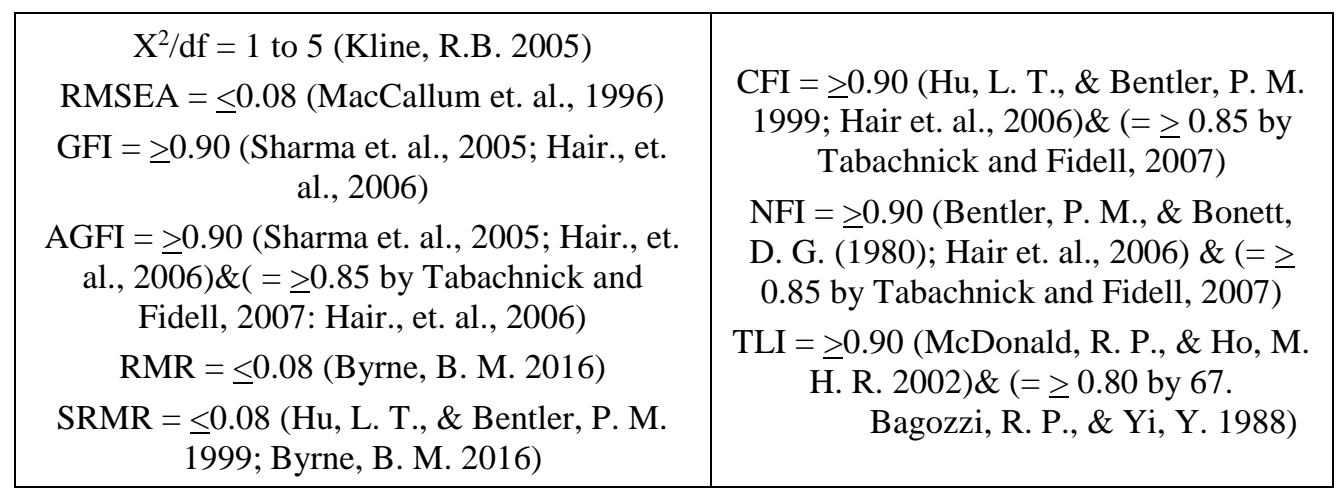

Global Business Dimensions: On the basis of goodness of fit index (GFI) value (0.934) and adjusted goodness of fit index (AGFI) value (0.917) indicating a good fit of the model, root mean square error of approximation (RMSEA) value (0.039) being below the threshold limit of (0.08) indicating hypothesized model fit of the data, normed fit index (NFI) value $(0.817)$ indicating a reasonably good fit of the model, the Tucker-Lewis coefficient (TLI) value (0.883) indicating a reasonably good fit of the model, the comparative fit index (CFI) value $(0.899)$ indicating a good fit of model and Chi-Square to degree of freedom (X2/df) ratio value (1.972) recommended range from 1 to 5 by Kline, R.B. (2005) and overall this absolute and incremental fit indices of global business dimensions indicating acceptable fit of the model, it is inferred that the globalization has impacted and transformed the important business dimensions that are included in the proposed research model.

Skill Dimensions: On the basis of goodness of fit index (GFI) value (0.924) and adjusted goodness of fit index (AGFI) value (0.903) indicating a good fit of the model, root mean square error of approximation (RMSEA) value (0.050) being below the threshold limit of (0.08) indicating hypothesized model fit of the data, normed fit index (NFI) value (0.884) indicating a reasonably good fit of the model, the Tucker-Lewis coefficient (TLI) value (0.903) indicating a reasonably good fit of the model, the comparative fit index (CFI) value (0.918) indicating a good fit of model and Chi-Square to degree of freedom (X2/df) ratio value (3.088) indicating acceptable fit of the model, it is inferred that the skill gaps have emerged in different business dimensions and a need felt to bridge these skill gaps.

Human Resource Dimensions: On the basis of goodness of fit index (GFI) value (0.910) and adjusted goodness of fit index (AGFI) value (0.890) indicating a good fit of the model, root mean square error of approximation (RMSEA) value (0.053) being below the threshold limit of (0.08) indicating hypothesized model fits the data, normed fit index (NFI) value (0.874) indicating a reasonably good fit of the model, the Tucker-Lewis coefficient (TLI) value (0.903) indicating a reasonably good fit of the model, the comparative fit index (CFI) value (0.914) indicating a good fit of model and Chi-Square to degree of freedom (X2/df) ratio value (2.815) indicating acceptable fit of the model, it is inferred that the human resource policies and initiative are found inadequate by the respondents across the grades.

Motivational Dimensions viz Motivation, Job Satisfaction and Career Orientation: On the basis of goodness of fit index (GFI) value (0.956) and adjusted goodness of fit index (AGFI) value $(0.928)$ indicating a good fit of the model, root mean square error of approximation 
(RMSEA) value (0.069) being below the threshold limit of (0.08) indicating hypothesized model fits the data, normed fit index (NFI) value (0.882) indicating a reasonably good fit of the model, the Tucker-Lewis coefficient (TLI) value (0.872) indicating a reasonably good fit of the model, the comparative fit index (CFI) value (0.907) indicating a good fit of model and Chi-Square to degree of freedom (X2/df) ratio value (4.102) indicating reasonable fit of the model relating to motivational dimensions, it is revealed that the human resource policy initiatives have a direct relationship with motivation and job satisfaction which in turn have significant career orientation. Inadequacy of appropriate HR Policy initiatives was one of the indicators of lower level of motivation and job satisfaction across the grades of officers.

\section{Identification of skill gap}

- Grade: The value of F (2.317) being greater than P value (0.099) at $10 \%$ level of significance substantiated the fact that there was significant difference in the mean scores of respondents in the different grades with respect to identification of skill gaps.

- Specialization: The value of F (0.044) being lesser than $\mathrm{P}$ value $(0.957)$ at $10 \%$ level of significance substantiated the fact that there was no significant difference in the mean scores of respondents in the different specializations with respect to identification of skill gaps.

- Length of Service: The value of F (0.928) being greater than P value $(0.427)$ at $1 \%$ level of significance substantiated the fact that there was significant difference in the mean scores of respondents in the different length of service with respect to identification of skill gaps.

- Working Bank Size: The value of F (1.107) being greater than P value $(0.331)$ at $5 \%$ level of significance substantiated the fact that there was significant difference in the mean scores of respondents in the different working bank size with respect to identification of skill gaps.

- Geographical Location: The value of F (1.056) being greater than P value (0.367) at $5 \%$ level of significance substantiated the fact that there was significant difference in the mean scores of respondents in the different geographical locations with respect to identification of skill gaps.

\section{Sources to Bridge skill gaps}

- Grade: The value of F (2.666) being greater than P value (0.070) at $10 \%$ level of significance substantiated the fact that there was significant difference in the mean scores of respondents in the across grade with respect to sources to bridge skill gaps.

- Specialization: The value of F (0.436) being lesser than P value (0.647) at $10 \%$ level of significance substantiated the fact that there was no significant difference in the mean scores of respondents in the across specialization with respect to sources to bridge skill gaps.

- Length of Service: The value of F (2.938) being greater than P value (0.033) at $10 \%$ level of significance substantiated the fact that there was significant difference in the mean scores of respondents in the across length of service with respect to sources to bridge skill gaps.

- Working Bank Size: The value of F (1.645) being greater than P value (0.194) at 5\% level of significance substantiated the fact that there was significant difference in the 
mean scores of respondents in the across working bank sizes with respect to sources to bridge skill gaps.

- Geographical Location: The value of F (0.525) being lesser than P value $(0.665)$ at $5 \%$ level of significance substantiated the fact that there was no significant difference in the mean scores of respondents in the across geographical location with respect to sources to bridge skill gaps.

\section{Implication Of This Study}

Many business dimensions during the last two and half decades of globalization have undergone transformation leading to skill gaps in existing workforce for managing such changes. The resultant deficiency in skill sets posed serious constraints in accomplishing the tasks which led to reduced level of job satisfaction, career orientation and motivation. The sudden emergence of vast skill gaps in the Indian Public Sector Banks posed a challenge to address the vital issue of narrowing down the skill gaps. The introduction of modern technology and a wide range of diversified products including Universal Banking rendered the large sections of the employees lesser equipped to meet the challenge. With the growing focus on business process reengineering to simplify the processes, the use of modern technology became an important and indispensable imperative. Such a situation called for reequipping and reskilling the entire work force which did pose the constraints of adaptability on the part of older set of employees who preferred to take an exit route offered to them through an instrument of Special Voluntary Retirement Scheme with an attractive Golden Hand Shake. It resulted in a significant reduction of manpower across the grades. There was a need felt for better coordination between functional heads and HR managers of Public Sector Banks. It also assumed greater significance in the wake of designing of new training programs to re-skill and up-skill the employees. Even the trainers needed fresh training to enhance their effectiveness. It is in this back drop that the conceptual model developed as part of this study could be taken as a basis to redesign HR Policies and practices to enhance the capability of employees thereby leading to enhanced level of motivation across the organizations.

\section{Conclusion}

The Skill Gap Theory of Motivation brings out the importance of skills required in the organisation to perform the task. It is not always the case that the skills possessed or acquired by the employees would perfectly match the required skills. If there are skill gaps, it would lead to a lack of confidence to accomplish the task well. A situation would get created wherein the employees with skill gaps would not feel enthusiastic to accomplish the task assigned to them. This leads to lower levels of performance outcome impacting the employee behavior and eventually lowering the level of motivation. The proposed model provides for bridging the skill gaps with the help of Training and Development, Better Skill Management, Suitable Monetary Compensation, Better Career Prospects as Work Place Factors and Leadership Styles, Peace of Mind and Better Accountability Perceptions as Professional Factors.

The proposed Skill Gap Model of Motivation will help the organisation to design suitable Work Place Factors and Professional Factors so as to reduce the Skill Gaps and enhance the motivation of its employees. The organizations will thus stand greatly benefitted by the application of new model. 
The proposed Skill Gap Model of Motivation will help the academic world to have the benefit of proposed theory of motivation and enhance the quality of management education and literature in the field of Human Resource Management. While the new theory will help in bridging the Skill Gap in the organisation, it will also help in bridging the gap in the theories of motivation in the existing literature.

\section{References}

[1]. Aasheim, Cheryl L., Li, Lixin., Williams, Susan. (2009). Knowledge and skill requirements for entry-level information technology workers: A comparison of industry and academia. Journal of information systems education, 20(3), 349.

[2]. Abbasi, F. K., Ali, A., \& Bibi, N. (2018). Analysis of skill gap for business graduates: managerial perspective from banking industry. Education+ Training, 60(4), 354-367.

[3]. Ainslie, G. (1992). Picoeconomics: The strategic interaction of successive motivational states within the person. Cambridge University Press.

[4]. Alderfer, C. P. (1969). An empirical test of a new theory of human needs. Organizational behavior and human performance, 4(2), 142-175.

[5]. Anna Salanova and Sanni Kirmanen (2010). Employee Satisfaction and Work Motivation - Research in Prisma Mikkeli, Bachelor's Thesis - Business Management, Mikkeli University of Applied Science, (Retrieved from :

[6]. Argyris, C. (1970). Intervention theory and method. Reading, Mass.

[7]. Argyris, C., \& Schon, D. A. (1974). Theory in practice: Increasing professional effectiveness. Jossey-Bass.

[8]. Argyris, C., \& Schön, D. A. (1997). Organizational learning: A theory of action perspective. Reis, (77/78), 345-348.

[9]. Bagozzi, R. P., \& Yi, Y. (1988). On the evaluation of structural equation models. Journal of the academy of marketing science, 16(1), 74-94.

[10]. Baskara Mohan, D. C. J. (2013). A Study On Hrm Practices And Its Impact On Globalisation Of Indian Business. IOSR Journal of Business and Management, 9(4), 34-36. doi:10.9790/487x-0943436

[11]. Bentler, P. M., \& Bonett, D. G. (1980). Significance tests and goodness of fit in the analysis of covariance structures. Psychological bulletin, 88(3), 588.

[12]. Brown, T. A., \& Moore, M. T. (2012). Confirmatory factor analysis. Handbook of structural equation modeling, 361-379.

[13]. Byrne, B. M. (2016). Structural equation modeling with AMOS: Basic concepts, applications, and programming. Routledge.

[14]. Cox, W. M., \& Klinger, E. (Eds.). (2011). Handbook of motivational counseling: Goalbased approaches to assessment and intervention with addiction and other problems. John Wiley \& Sons.

[15]. Davidson, D. (1963). Actions, reasons, and causes. The journal of philosophy, 60(23), 685-700.

[16]. Di Salvo, V. S., \& Larsen, J. K. (1987). A contingency approach to communication skill importance: The impact of occupation, direction, and position. The Journal of Business Communication (1973), 24(3), 3-22.

[17]. Dornyei, Z., \& Ottó, I. (1998). Motivation in action: A process model of L2 motivation. [18]. Eccles, J. S., \& Wigfield, A. (2002). Motivational beliefs, values, and goals. Annual review of psychology, 53(1), 109-132.

[19]. Elnaga, A., \& Imran, A. (2013). The effect of training on employee performance. European Journal of Business and Management, 5(4), 137-147. 
[20]. Fiske, S. T., \& Taylor, S. E. (2013). Social cognition: From brains to culture. Sage.

[21]. Gardner, T. M., Wright, P. M., \& Moynihan, L. M. (2011). The impact of motivation, empowerment, and skill-enhancing practices on aggregate voluntary turnover: The mediating effect of collective affective commitment. Personnel psychology, 64(2), 315-350.

[22]. Goodman, J. M., Evans, W. R., \& Carson, C. M. (2011). Organizational politics and stress: Perceived accountability as a coping mechanism. The Journal of Business Inquiry, 10(1), 66-80.

[23]. Hair Jr, J. F., Hult, G. T. M., Ringle, C., \& Sarstedt, M. (2016). A primer on partial least squares structural equation modeling (PLS-SEM). Sage Publications.

[24]. Hair, J. F., Black, W. C., Babin, B. J., Anderson, R. E., \& Tatham, R. L. (2006). Multivariate data analysis (Vol. 6).

[25]. Harrington, D. (2009). Confirmatory factor analysis. Oxford University Press.

[26]. Herzberg, F., Snyderman, B. B., \& Mausner, B. (1966). The Motivation to Work: 2d Ed. J. Wiley.

[27]. Hooper, D., Coughlan, J., \& Mullen, M. (2008). Structural equation modelling: Guidelines for determining model fit. Articles, 2.

a. https://www.theseus.fi/bitstream/handle/10024/10979/Salanova_Anna_Kirmanen_Sanni.pdf) [28]. Hu, L. T., \& Bentler, P. M. (1999). Cutoff criteria for fit indexes in covariance structure analysis: Conventional criteria versus new alternatives. Structural equation modeling: a multidisciplinary journal, 6(1), 1-55.

[29]. Karthikeyan, K., Karthi, R., and Shyamala Graf (2010). Impact of Training in Indian Banking Sector-An Empirical Investigation. International Journal of Business and Management, 5(7), 77-83.

[30]. Kavita Rani and Diksha Garg (2014). A Study on Training and Development in Public Sector Banks, International Journal of Management and Social Sciences Research (IJMSSR), 3(1), 33-37.

[31]. Kim, J. H. (2011). Issue leadership as a mediator between self-efficacy/initiative behavior and leadership effectiveness/innovativeness. The Korean Journal of Human Resource Development Quarterly, 13(2), 149-168.

[32]. Kleinginna, P. R., \& Kleinginna, A. M. (1981). A categorized list of motivation definitions, with a suggestion for a consensual definition. Motivation and emotion, 5(3), 263291.

[33]. Kline, R. B. (2015). Principles and practice of structural equation modeling. Guilford publications.

[34]. Kogut, B., \& Zander, U. (1992). Knowledge of the firm, combinative capabilities, and the replication of technology. Organization science, 3(3), 383-397.

[35]. Kopelman, R. E., Prottas, D. J., \& Davis, A. L. (2008). Douglas McGregor's theory X and Y: Toward a construct-valid measure. Journal of Managerial Issues, 255-271.

[36]. Kuchinke, K. P. (1998). 'The influence of leadership styles on subordinates' attitudes towards their leaders and towards performance: A comparison of US and German manufacturing employees. Human Resource Development International, 1(3), 291-308.

[37]. Lawler III, E. E., \& Suttle, J. L. (1973). Expectancy theory and job behavior. Organizational Behavior and Human Performance 9, 482-503.

[38]. Lee, S. (2007). Vroom's expectancy theory and the public library customer motivation model. Library Review, 56(9), 788-796.

[39]. Linjuan Rita Men (2014). Strategic internal communication: Transformational leadership, communication channels, and employee satisfaction. Management Communication Quarterly, 28(2), 264-284. 
[40]. Linjuan Rita Men (2014). Why leadership matters to internal communication: Linking transformational leadership, symmetrical communication, and employee outcomes. Journal of Public Relations Research, 26(3), 256-279.

[41]. Locke, E. A., \& Latham, G. P. (2002). Building a practically useful theory of goal setting and task motivation: A 35-year odyssey. American psychologist, 57(9), 705.

[42]. Lynham, S. A. (1998). The development and evaluation of a model of Responsible Leadership for Performance. Human Resource Development International, 1(2), 207-220. doi:10.1080/13678869800000025

[43]. MacCallum, R. C., Browne, M. W., \& Sugawara, H. M. (1996). Power analysis and determination of sample size for covariance structure modeling. Psychological methods, 1(2), 130.

[44]. Madan, P., \& Bajwa, J. K. (2015). Employee Retention Strategies in Banking Industry: A Study on Public and Private Sector Banks. International Journal of Social and Allied Research (IJSAR), 3(3), 91-94.

[45]. Malhotra, G. (2011). Analysing pre and post-liberalisation impact on Indian industries. International Journal of Business and Globalisation, 7(2), 232-253.

[46]. Manzoor, Q. A. (2012). Impact of employees motivation on organizational effectiveness. Business management and strategy, 3(1), 1-12.

[47]. Marcel Simard \& Alain Marchand. (1997). Workgroups' propensity to comply with safety rules: The influence of micro-macro organisational factors. Ergonomics, 40(2), 172 188, DOI: $10.1080 / 001401397188288$.

[48]. Marsh, H. W., Morin, A. J., Parker, P. D., \& Kaur, G. (2014). Exploratory structural equation modeling: An integration of the best features of exploratory and confirmatory factor analysis. Annual review of clinical psychology, 10, 85-110.

[49]. Maslow, A. (1954). Motivation and Personality-New York-Hardper and Row.

[50]. Maslow, A. H. (1943). A theory of human motivation. Psychological review, 50(4), 370.

[51]. Maslow, A. H. (1962). Toward a psychology of being, Princeton (D. van Nostrand Company) 1962.

[52]. McClelland, D. C. (1965). Toward a theory of motive acquisition. American psychologist, 20(5), 321.

[53]. McDonald, R. P., \& Ho, M. H. R. (2002). Principles and practice in reporting structural equation analyses. Psychological methods, 7(1), 64.

[54]. McGregor, D. (1960). Theory X and theory Y. Organization theory, 358-374.

[55]. McGregor, D. (2006). The human side of enterprise. McGraw Hill Professional.

[56]. McGregor, D. M. (1967). The Professional Manager. Eds. W. G. Bennis and C. McGregor. New York, NY: McGraw-Hill.

[57]. Meyer, J. P., Becker, T. E., \& Vandenberghe, C. (2004). Employee commitment and motivation: a conceptual analysis and integrative model. Journal of applied psychology, 89(6), 991.

[58]. Mulaik, S. A. (1988). Confirmatory factor analysis. In Handbook of multivariate experimental psychology (pp. 259-288). Springer, Boston, MA.

[59]. Neely, A., Gregory, M., \& Platts, K. (2005). Performance measurement system design: A literature review and research agenda. International journal of operations \& production management, 25(12), 1228-1263.

[60]. Neil Kokemuller and Demand Media (2012) "what is the Meaning of Business Organization?" (Retrived from : www.smallbusiness.chron.com/meaning-businessorganization-41925.html) 
[61]. Porter, L. W. (1962). Job attitudes in management: I. Perceived deficiencies in need fulfillment as a function of job level. Journal of applied Psychology, 46(6), 375.

[62]. Porter, L. W., \& Lawler, E. E. (1968). Management attitudes and performance. Homewood IL.: Richard D. Irwin Company.

[63]. Robert C. Merchant, Jr. The Role of Career Development in Improving Organizational Effectiveness and Employee Development. (Retrieved from: http://docplayer.net/6121973The-role-of-career-development-in-improving-organizational-effectiveness-and-employeedevelopment.html)

[64]. Rousseau, D. M., \& Fried, Y. (2001). Location, location, location: Contextualizing organizational research. Journal of Organizational Behavior: The International Journal of Industrial, Occupational and Organizational Psychology and Behavior, 22(1), 1-13.

[65]. Shamir, B., House, R. J., \& Arthur, M. B. (1993). The motivational effects of charismatic leadership: A self-concept based theory. Organization science, 4(4), 577-594.

[66]. Sharma, S., Mukherjee, S., Kumar, A., \& Dillon, W. R. (2005). A simulation study to investigate the use of cutoff values for assessing model fit in covariance structure models. Journal of Business Research, 58(7), 935-943.

[67]. Sheldon, K. M., \& Elliot, A. J. (1999). Goal striving, need satisfaction, and longitudinal well-being: the self-concordance model. Journal of personality and social psychology, 76(3), 482.

[68]. Shiri, S. (2014). Impact of Globalisation-Integration And Transformation of Hr as A Strategic Partner in Business Operations. Global Journal For Research Analysis, 3(7), 193195.

[69]. Spencer, L. M., \& Spencer, P. S. M. (2008). Competence at Work models for superior performance. John Wiley \& Sons.

[70]. Stipek, D. J. (1996). Motivation and instruction. Handbook of educational psychology, 85-113.

[71]. Urwick, L. F. (1970). Theory Z. SAM Advanced Management Journal, 35(1), 14-21.

[72]. Voon, M. L., Lo, M. C., Ngui, K. S., \& Ayob, N. B. (2011). The influence of leadership styles on employees' job satisfaction in public sector organizations in Malaysia. International Journal of Business, Management and Social Sciences, 2(1), 24-32.

[73]. Vroom, V. (1964). Work and Motivation (John Wilely and Sons, New York).

[74]. Wigfield, A., \& Guthrie, J. T. (2000). Engagement and motivation in reading. Handbook of reading research, 3, 403-422.

[75]. Yongbeom Kim., Jeffrey Hsu., and Mel Stern (2006). An update on the IS/IT skills gap. Journal of information systems education, 17(4), 395.

\section{Annexure - 1}

The 25 Indian Public Sector Banks were categorised into three such as 'large', 'medium' and 'small' in accordance with the size of their business mix as under:

Large Banks Bank of Baroda, Punjab National Bank, Bank of India, Canara Bank, Union Bank of India and Central Bank of India

Medium Banks

Allahabad Bank, Indian Bank, Indian Overseas Bank, Oriental Bank of Commerce, Syndicate Bank and UCO Bank 


\section{Small Banks}

Andhra Bank, Bank of Maharashtra, Corporation Bank, Dena Bank, Punjab \& Sind Bank, United Bank of India and Vijaya Bank. 